\title{
ANÁLISE ESTRATÉGICA NERINT
}

A aceleração do ritmo dos acontecimentos e processos internacionais requer uma análise qualificada de conjuntura, sem o viés político-jornalístico que, muitas vezes, as caracterizam. Além de artigos teórico-analíticos, faz-se necessário publicar uma breve avaliação de acontecimentos marcantes. Para tanto, o Núcleo Brasileiro de Estratégia e Relações Internacionais (NERINT), integrante de Centro de Estudos Internacionais sobre Governo (CEGOVUFRGS), lançou a Análise Estratégica NERINT, com a contribuição de seus pesquisadores especializados e de convidados com expertise temática.

Ela será publicada ao final de cada volume da Austral: Revista Brasileira de Estratégia e Relações Internacionais, iniciando com uma avaliação da Diplomacia Pós-Trump, dos conflitos no entorno da Rússia e das Lições Estratégicas da II Guerra Mundial em seu $75^{\circ}$ aniversário. Desde os anos I990 o Itamaraty vem defendendo a formação de quadros acadêmicos qualificados nacionais sobre temas e países relevantes para a diplomacia, os negócios e a defesa do Brasil. O esforço de formação dos mesmos, via fomento de pós-graduação, está dando resultados, e o Brasil já conta com professores e pesquisadores de nível internacional.

\section{A ELEIC̣ÃO DA BIELORRÚSSIA/BELARUS E SUAS DIMENSÕES INTERNACIONAIS}

Rodrigo Ianhez Historiador pela Universidade Estatal de Moscou

Há uma falsa impressão de que o conflito deflagrado após as eleições presidenciais deste ano na Bielorrússia é mais uma vez explicado pela simplista dicotomia entre Rússia e Ocidente. Mais simplista ainda é a interpretação de que 
os russos estariam apoiando o presidente bielorrusso Aleksandr Lukashenko, que desde o princípio seria tido como adversário pelos países da União Europeia e da OTAN. Já desde a crise na Ucrânia, em 2014, Lukashenko vem se afastando da Rússia, e esse processo se acelerou nos últimos anos e atingiu seu ápice no início de 2020. O presidente passou a valorizar mais a língua bielorrussa e enfatizar o nacionalismo em oposição à aproximação com Moscou que vigorava anteriormente.

Ainda em relação ao conflito entre Rússia e Ucrânia, Lukashenko posou de artífice da paz. Um documento representativo desse momento são as fotos dos acordos de Minsk: o bielorrusso é o único sorrindo (e o único com grandes motivos para tal). Essa intermediação proporcionou uma melhora nas relações com o Ocidente, através da qual Lukashenko enxergou uma oportunidade de sair da esfera de poder russa. Nunca se tratou de uma ruptura de fato, mas o presidente da Bielorrússia julgou que poderia se beneficiar de ambos os lados da disputa geopolítica. Ele já goza de uma excelente relação com a China, país que detém uma série de investimentos no país: os chineses construíram comunidades inteiras na Bielorrússia habitadas por trabalhadores vindos da China e Xi Jinping foi o primeiro a cumprimentar Lukashenko pela vitória nestas eleições tão contestadas de 2020 .

A aproximação com o Ocidente rendeu frutos: na eleição presidencial de 20I5, a União Europeia elogiou Lukashenko por sua postura, afirmou a legitimidade das eleições e com base nisso cancelou várias das sanções que ainda impunha sobre o país. Até então, os europeus sempre condenavam os processos eleitorais na Bielorrússia e reafirmavam a pecha de que o país se tratava da «última ditadura da Europa». Parecia que a estratégia estava dando certo, mas a UE esperava que Lukashenko seguisse com seu afastamento de Putin. Ele de fato seguiu esse curso até mesmo após as eleições e a intensificação das manifestações. Em janeiro deste ano, Lukashenko chegou a acusar o Kremlin de querer anexar a Bielorrússia, Putin cortou subsídios, e a situação entrou num processo de agravamento até julho, quando os bielorrussos prenderam vários funcionários de uma companhia de segurança russa, sob acusação de estarem promovendo instabilidade no país, com fins de provocar uma intervenção.

Nesse mesmo período, Lukashenko vinha conduzindo a crise do coronavírus de maneira um tanto desastrosa, como foi noticiado pelo mundo todo. Essa situação provocou uma brusca queda de popularidade em um momento chave, imediatamente anterior às eleições. Surgiram vários candidatos bem assessorados e com ambições palpáveis, em contraste com as eleições anteriores. Os principais eram Viktar Babariko, um banqueiro pró-Kremlin com conexões com a Gazprom, Valery Tsepkalo, ex embaixador 
nos EUA e um candidato tido como pró-Ocidente e Sergey Tikhonovski, um blogueiro que cresceu na onda da pauta anti-corrupção, análogo ao russo Aleksei Navalny. Lukashenko logo tratou de neutralizar seus adversários: Babariko e Tikhonovski foram presos e Tsepkalo abandonou o país. Entre as acusações, estava a interferência russa por meio da Gazprom, em conjunto com a candidatura de Babariko. É importante sublinhar que mesmo o candidato Tsepkalo. considerado mais pró-ocidental, se refugiou em Moscou, onde concluiu sua formação pelo prestigioso Instituto Estatal de Relações Internacionais de Moscou (MGIMO). O bloco ocidental permaneceu calado durante todos esses momentos, pois entendia que Lukashenko era a única pessoa prevenindo uma aproximação da Bielorrússia com a Federação da Rússia, aproximação essa que pudesse levar a uma eventual união entre os dois países.

A esposa do blogueiro Tikhonovki, a autodeclarada dona-de-casa Svetlana Tikhonovskaya, assumiu então a candidatura e prosseguiram com as eleições. Lukashenko ganhou com mais de $80 \%$, sob graves denúncias de fraude. Tikhonovskaya protocolou um pedido de recontagem dos votos e deixou a Bielorrússia para a Lituânia, de onde vem coordenando esse esforço para invalidar a eleição, agora já com apoio aberto da UE. Mais recentemente, entretanto, essa relação vem demonstrando sinais de esgarçamento, Tikhonovskaya reclamou das palavras vazias de líderes europeus que não se concretizam em ações efetivas contra o governo bielorrusso. É importante ainda ressaltar que a União Europeia e os EUA só passaram a criticar Lukashenko muito recentemente, quando perceberam a força dos protestos e também empurrados para a situação pelo bloco anti-Rússia de países como as repúblicas do Báltico e Polônia, que passaram a apostar na ampliação das manifestações e numa eventual contaminação da Rússia. A partir desse momento, a narrativa virou i8o graus, pois intuitivamente, e mal informados pela mídia ocidental, muitos acreditaram que Lukashenko teria apoio de Putin desde sempre e que o ocidente democrático jamais apoiaria o «último ditador da Europa».

O próprio Lukashenko mudou sua narrativa. No início dos protestos, ele chegou a acusar os russos de estarem por trás das manifestações, numa tentativa de derrubá-lo. Alguns veículos ocidentais replicaram essas teorias conspiratórias, chegando a fazer comparações com os «pequenos homens verdes» da Criméia. Um parlamentar polonês no Parlamento Europeu até pediu novas sanções contra a Rússia, justamente alegando intervenção russa contra Lukashenko na Bielorrússia. Nos últimos meses, grupos neonazistas poloneses atravessaram as fronteiras para participar das manifestações contra Lukashenko. Um desses fascistas foi agredido e acabou entrevistado pela BBC, 
como se fosse uma simples vítima da violência autoritária na Bielorrússia. A partir dessa escalada, Lukashenko começou a perceber a mudança de maré, e resolveu pedir apoio aos russos, falou diversas vezes com Putin e espera apoio. Até o presente momento, não está muito claro como e mesmo se o Kremlin vai agir. A mídia russa tem coberto os protestos extensivamente e com um tom bastante positivo em favor dos manifestantes, ressaltando a violência da repressão por parte das forças de segurança, em um claro contraste com a cobertura dos protestos na Ucrânia, em 2014 .

Sobre os manifestantes em si, como sempre vem ocorrendo na Europa Oriental, rapidamente os protestos foram dominados por liberais próocidente e por nacionalistas conservadores. Havia algumas vozes socialistas, mas elas foram caladas. A oposição ainda é bastante desorganizada e Svetlana Tikhonovskaya não conseguiu se firmar até agora como uma liderança efetiva. O ocidente cada vez mais está interferindo na situação, enquanto os russos ainda não se movimentam. A intensidade dos protestos tem altos e baixos, apesar de haver uma impressão de que a maioria dos descontentes está concentrada em Minsk. Mesmo sem fraudes, Lukashenko ainda teria obtido uma maioria dos votos, e sua base de apoio não foi totalmente erodida, ainda que sua posição pareça cada vez mais isolada. Ele está tentando ganhar tempo com uma proposta de constituinte por meio de referendo, mas não há uma movimentação conclusiva em direção a isso.

Moscou, I5 de dezembro de 2020.

\section{CONFLITO AZERBAIJÃO X ARMÊNIA: UMA GUERRA INDESEJADA PARA A RÚSSIA}

Rodrigo Ianhez Historiador pela Universidade Estatal de Moscou

No dia 9 de novembro de 2020 , após um curto conflito pela região de Nagorno-Karabakh (conhecida pelos armênios como República de Artsakh), Armênia e Azerbaijão assinaram um tratado de cessar-fogo. Na prática esse tratado representou uma capitulação por parte da Armênia, onde ainda hoje milhares de manifestantes se mobilizam contra os termos acordados e buscam provocar a renúncia do primeiro-ministro Nikol Pashinian. No Azerbaijão, o acordo foi recebido como uma grande vitória e deve garantir 
ao presidente Ilham Aliyev mais alguns anos de estabilidade no poder. Saem fortalecidas, ainda que de maneira incerta, as maiores potências regionais: Rússia e Turquia.

A natureza do conflito, bem como a política dos países envolvidos, é um tema bastante distante da realidade dos brasileiros. As poucas notícias que chegam ao país vêm filtradas pelos grandes grupos de mídia do Ocidente. Portanto, esta análise busca apresentar um breve panorama da situação para, em seguida, tratar de questões como as origens do conflito, o papel das partes envolvidas e as perspectivas a partir de agora e, desse modo, demonstrar como o papel da Federação da Rússia na resolução da questão não é apenas central, como é incontornável.

Muito se discute entre analistas ocidentais as origens dos conflitos de natureza étinico-religiosa na região do Cáucaso, em particular a contenda entre armênios e azeris. O fato é que o Cáucaso é um território estratégico e como tal, objeto de disputas históricas. Entre os mares Negro e Cáspio e recortado por cadeias de montanha, o Cáucaso é cobiçado desde os tempos do Império Romano e atraiu, ao longo dos séculos, invasores de diversas potências estrangeiras. Suas características geográficas peculiares, no entanto, garantiram que nenhum domínio estrangeiro perdurasse no longo prazo. Por outro lado, os diferentes grupos étnicos que habitam a região e, mais importante, as tensões entre cristãos e muçulmanos, fizeram com que o Cáucaso fosse um caldeirão em ebulição, sempre prestes a transbordar. O presente conflito é resultado desses séculos de embates e o elemento étnicoreligioso é, portanto, central.

As tensões entre armênios e azeris transbordaram na esteira da crise na URSS, ao longo da década de I980. O epicentro dessas tensões é a região de Nagorno-Karabakh, de maioria armênia e que na década de I920 foi colocada por Moscou sob administração dos azeris. No período, Armênia, Azerbaijão e Geórgia ainda formavam uma única República Transcaucásia dentro da União Soviética, que foi dividida posteriormente em três repúblicas com o mesmo nível de autonomia, com Nagorno-Karabakh ainda sob controle do Azerbaijão. Apesar do descontentamento, esse arranjo perdurou de maneira pacífica até a crise derradeira do regime comunista, quando, já em I988, começaram as altercações entre os dois povos. Após a dissolução da URSS em I99I, a situação rapidamente escalou para uma guerra na qual os armênios não apenas tomaram Nagorno-Karabakh, como ocuparam territórios ao redor do exclave, que não possuía fronteiras com o território principal da Armênia.

Esse quadro de instabilidade nos últimos anos da União Soviética alimenta uma fórmula que, ainda que reciclada da Guerra Fria, é aplicada recorrentemente nos dias de hoje, não apenas para o Cáucaso, mas também 
para a Ásia Central e outras regiões do espaço pós-soviético. Trata-se da ideia de que a URSS teria estimulado a divisão e a desconfiança entre as diferentes nacionalidades que compunham seu sistema federativo para que os conflitos internos não pudessem ser solucionados sem a intervenção de Moscou, sendo uma variante da estratégia britânica de dividir para reinar. As consequências da cizânia semeada pelo Kremlin estariam no cerne dos inúmeros conflitos que ainda assolam as antigas repúblicas pós-soviéticas. Essa narrativa simplista seria a chave para compreender conflitos que vão da Criméia à Tchetchênia, passando por Ossétia, Abkhazia, Transnístria e claro, Nagorno-Karabakh.

Tal formulação ignora, entretanto, séculos de guerras, perseguições e contendas que, no caso do Cáucaso, são ainda mais relevantes. Para as civilizações cristãs da região, Geórgia e Armênia, os séculos que antecederam o período soviético foram marcados pela dominação pelos impérios otomano e persa e pelas constantes altercações com os povos muçulmanos do Cáucaso Norte. Para os armênios, estes atritos culminaram em uma tragédia de proporções descomunais: o genocídio perpetrado pelo Império Otomano a partir de I9I5. Ao observarmos a totalidade do quadro que remonta a conflitos milenares em uma região comprimida entre grandes potências, não é possível ignorar que os cerca de 70 anos de dominação soviética foram marcados por rara estabilidade.

Em consonância com esta ideia de que a URSS foi determinante para criar as condições que levariam ao conflito entre Azerbaijão e Armênia, está a narrativa imprecisa de que a presente atuação da Federação Russa tem sido mal recebida pelos aliados armênios. Muito se especula sobre as intenções do governo de Vladimir Putin e sobre sua verdadeira relação com a administração do primeiro-ministro Pashinian. De fato, Nikol Pashinian chegou ao poder em 2018 por meio de protestos que derrubaram o governo de Serge Sarksian, aliado próximo dos russos. A atuação anterior de Pashinian enquanto parlamentar, foi de maior aproximação com os Estados Unidos e Europa, o que por vezes gerou conjecturas de que sua administração se afastaria da Rússia. Esse fator, somado à prisão por parte do governo Pashinyan de um grande aliado russo na política armênia, o ex-presidente Robert Kotcharyan ${ }^{\mathrm{I}}$ , levantou dúvidas sobre a disposição do novo primeiro-ministro em relação à Federação Russa. É impossível determinar qual foi de fato a intenção inicial do novo primeiro-ministro da Armênia, mas podemos afirmar com segurança que Nikol Pashinyan buscou sinalizar em diversas ocasiões que faria a manutenção dos compromissos entre russos e armênios.

A conjuntura na qual a Armênia está inserida transforma a hipótese de

I Ver em: https://www.rbc.ru/politics/28/07/2020/5fIfderega7947a5443a2706?from=from_ main_I. 
ruptura com a Federação Russa em uma impossibilidade geopolítica. Como foi possível perceber durante o conflito recente, a Armênia se vê cercada por dois rivais, a Turquia e o Azerbaijão, ao mesmo tempo em que sustenta uma relação de pouca cooperação com a Geórgia. De fato, o único vizinho imediato com que os armênios cultivam uma proximidade é o Irã, com quem dividem uma fronteira pequena e vulnerável, em uma região agora espremida entre o território recém recuperado pelo Azerbaijão e o exclave azeri de Nakhitchevan. A Rússia, por sua vez, apesar de não possuir fronteiras com a Armênia, mantém uma de suas únicas bases em território estrangeiro na segunda maior cidade armênia, Gyumri. Além disso, a Armênia é membro, junto com a Federação Russa, da Organização do Tratado de Segurança Coletiva, aliança militar que determina que seus membros têm responsabilidade de intervenção no caso de violação do território de qualquer dos signatários. Essas garantias, que não se estendem ao território considerado ocupado de Nagorno-Karabakh, são a principal razão pela qual o Azerbaijão não tem qualquer incentivo para avançar sobre as fronteiras internacionalmente reconhecidas da Armênia.

Um sinal de que Nikol Pashinyan comprende a posição delicada da Armênia seriam seus numerosos encontros com Vladimir Putin ${ }^{2}$, em um gesto que sinalizou para o Kremlin a intenção de afastar os rumores sobre uma suposta guinada da política externa armênia. De maneira semelhante, não há qualquer indício de que a opinião popular entre os armênios tenha se voltado contra a Rússia, a despeito das elucubrações da mídia ocidental. De fato, uma parcela específica de membros da diáspora, alguns dos quais têm retornado à Armênia nos últimos anos, cultiva sentimentos ambíguos em relação à Federação Russa, calcados ainda em animosidades que datam da Guerra Fria. Entre os armênios de origem soviética, no entanto, não há qualquer sinal de indisposição em relação aos russos. Em meio às ex-repúblicas soviéticas, a Armênia sempre figurou como uma das que melhor preserva seus laços históricos com a Rússia. Ainda que houvesse algum sentimento de abandono pelos aliados, diversos depoimentos colhidos após a assinatura do cessar-fogo do início de novembro demonstram que essa proximidade não foi abalada de maneira significativa. Pelo contrário, muitos armênios, especialmente em Nagorno-Karabakh, se sentem gratos e aliviados pela chegada de tropas de paz russas ${ }^{3}$. As manifestações de apoio foram tais que a mídia ocidental foi obrigada a mudar sua narrativa inicial de que a atuação do Kremlin estava sendo condenada pela opinião popular.

Permanece, entretanto, a questão do porquê Pashinian não recorreu

2 Ver em: https://eadaily.com/ru/news/20I9/II/ı3/pashinyan-otnosheniya-armenii-i-rossiirazvivayutsya-po-voshodyashchey.

3 Ver em: https://www.rt.com/russia/507I96-armenia-ally-gratitude-survey/. 
aos russos mais cedo no conflito. Ainda que possa parecer surpreendente a rapidez com que as tropas azeris avançaram sobre o terreno montanhoso de Nagorno-Karabakh, não havia qualquer dúvida em relação à superioridade da atual capacidade militar do Azerbaijão. Por sua vez, a Rússia mantém boa relação com os dois lados, mas tem obrigações formais com a Armênia, reforçadas pela presença de uma base militar no país. A posição de Pashinian ficou ainda mais fragilizada após o presidente russo ter afirmado que, ainda no início das hostilidades, teria convencido Ilham Aliyev em deter o avanço de suas tropas, de modo que o Azerbaijão tomaria apenas uma pequena porção do território de Karabakh4. Sua contraparte armênia teria considerado os termos inaceitáveis, o que levou à imposição de termos muito mais duros, que incluem a perda da cidade de Shushi e a garantia de passagem pelo corredor de Lachin. Essa afirmação vai de encontro com a ideia de que os russos teriam deixado a situação escalar, de modo a reafirmar a dependência do país caucasiano em relação à Federação da Rússia.

De toda maneira, é improvável que Nikol Pashinian sobreviva à crise política deflagrada pelas condições vexaminosas em que a Armênia se viu obrigada a baixar as armas. A retórica crescentemente belicosa de Aliyev e seu aliado Erdogan, demonstrada com pompa em uma parada militar realizada em Baku ${ }^{5}$ e em repetidas ocasiões nas últimas semanas, assim como escaramuças entre as partes do conflito tem testado os limites do acordo de cessar-fogo. Episódios como a tentativa de tomada de uma área de mineração de ouro em Sotk ${ }^{6}$ e de vilas ao Sul do corredor de Lachin, ambas regiões pertencentes ao território principal da Armênia, impeliram os russos a expandir a área de atuação das tropas de paz7 . De modo semelhante, é a atuação do Kremlin que impede a Turquia de impor ainda mais sua autoridade no Cáucaso.

A presença de tropas de manutenção de paz russas em NagornoKarabakh é uma realidade que deve perdurar pelos próximos anos. Resta saber se ela não gerará atritos que colocarão em risco as boas relações do país com o Azerbaijão, e mais importante, se não vai reviver as animosidades com a Turquia. No presente momento, a Rússia é a única garantia de não violação da integridade territorial da Armênia, por mais amargo que esse arranjo possa parecer para Ierevan.

Moscou, I5 de dezembro de 2020

4 Ver em: https://ria.ru/2020III7/armeniya-158508516r.html.

5 Ver em: https://www.rbc.ru/politics/10/12/2020/5fdrb8f89a7947978015oeed.

6 Ver em: https://www.rbc.ru/rbcfreenews/5fd64bb79a79475eb3a6f9I3.

7 Ver em: https://www.rbc.ru/rbcfreenews/5fd64bb79a79475eb3a6f9r3. 


\title{
LIC̣ÕES ESTRATÉGICAS DA II GUERRA MUNDIAL, 75 ANOS DEPOIS
}

\author{
José Miguel Quedi Martins \\ Professor Rel. Internacionais/UFRGS
}

A Segunda Guerra Mundial foi a maior e mais letal conflagração da história. Além de estender-se por todo o globo terrestre, destacou-se também por sua magnitude e intensidade. Estima-se que tenha envolvido diretamente mais de cem milhões de pessoas e causado 85 milhões de mortes, sendo pela primeira vez utilizadas as armas nucleares. Decorridos 75 anos do seu fim, e pouco mais de um século do término da Primeira Guerra Mundial, o mundo encontra-se novamente em uma espiral de tensões que podem, mais uma vez, redundar em uma guerra mundial. Este é o principal sentido de atualidade da Segunda Guerra, posto que as raízes das atuais tensões podem ser encontradas no balanceamento estrito que conduziu àquela conflagração e à Guerra Fria que a sucedeu.

O termo "balanceamento" expressa, em sentido amplo, a noção de que os Estados competem entre si, procurando limitar a liberdade de ação uns dos outros. O que pode envolver a possibilidade da ameaça ou do emprego da força - neste último caso, tem-se o que ora denomina-se balanceamento estrito. Deste modo, em seu sentido amplo, o balanceamento confunde-se com o próprio conceito de Relações Internacionais enquanto tal. Já em seu sentido estrito, pode caracterizar-se pela intimidação ou chantagem. Assim, é razoável correlacionar balanceamento amplo com dissuasão (deterrence), e balanceamento estrito com intimidação (compellence). Naturalmente, o exercício da intimidação exige superabundância de força. Daí o porquê de as Grandes Potências lançarem mão de "delegados", isto é, aliados que são empregados para "dividir o fardo" dos custos de segurança. Tal divisão internacional do trabalho de segurança, por vezes, acaba por dotar estes aliados de capacidades que os permitem assumir uma posição desafiante.

Foi este o caso da Alemanha, da Itália e do Japão - as potências desafiantes na II Guerra Mundial. A Alemanha, que resultou do desejo britânico de balancear a França - função cumprida originalmente pela Prússia - acabou por constituir-se em uma potência mais formidável do que aquela. O Japão, da intenção de manter a China subjugada (I894-95) e balancear a Rússia (I904-05) e a URSS (I918-25), acabou por destruir a hegemonia naval inglesa. As esquadras britânicas no Índico e no Extremo Oriente, Forças A, B 
e Z - que materializavam quase dois séculos de hegemonia naval britânica -, foram destruídas em um curto intervalo de tempo (Io/I2/I94I-IO/O4/I942). Mesmo com a Itália, em medida considerável, deu-se o mesmo. Como consequência, logo da eclosão da Segunda Guerra, o Almirantado Britânico considerava a Itália a maior ameaça à Royal Navy no Mediterrâneo. Daí o ataque surpresa realizado pelos ingleses em Taranto (II-I2/II/I940).

Com o benefício do distanciamento temporal, pode se dizer que este pequeno grupo de Estados-nação nunca teve chance contra os três Estadosregião (EUA, Rússia e China) e o Império Britânico, que se aliaram contra eles. Naturalmente, isso não diminui o mérito ou o heroísmo daqueles que combateram contra o Eixo. Contudo, mesmo nos momentos mais sombrios que se seguiram às vitórias fulgurantes do Eixo no biênio I940-4I, poucos duvidavam da vitória final dos aliados. Deste modo - e Paulo Visentini foi um dos primeiros a descortinar isso no Brasil - a II Guerra ocultou uma outra "guerra", a travada entre os próprios aliados. Particularmente, a da GrãBretanha contra a URSS e a China. A conduta adotada pelos ingleses, apesar de torpe - posto que prolongou a conflagração -, deve ser considerada como característica da ótica do balanceamento estrito.

O enfoque britânico foi praticamente o oposto ao adotado pelos estadunidenses. Os americanos passaram a planejar a abertura da segunda frente contra a Alemanha no calor da Batalha de Moscou (I94I). Ainda em I942 foi organizada a Operação Sledgehammer e, para ser desenrolada em I943, foi planejada a Operação Roundup. Ambas tinham como objetivo a invasão da Europa pelo Sul da França. Os dois intentos acabaram sendo frustrados pelos britânicos, em benefício da invasão do Norte da África com a Operação Torch (I942). Para além da projetada segunda frente, que visava aliviar a URSS, os EUA promoveram a Lei do Empréstimo e Arrendamento. Ela foi decisiva para os esforços de guerra soviético e chinês, sendo que neste último país, os EUA mantinham relações estreitas não apenas com os nacionalistas, mas também com os comunistas. Em suma, o enfoque predominante adotado pelos EUA, mesmo em meio à conflagração, foi o do engajamento ou cooperação, não a do balanceamento estrito.

A barganha diplomática empreendida pelo Brasil também ilustra o engajamento e não o balanceamento estrito. Foi graças às relações estreitas, originalmente mantidas tanto com a Alemanha quanto com os EUA, que o Brasil obteve os recursos e a tecnologia para construir a Companhia Siderúrgica Nacional em Volta Redonda. Vargas e Góes Monteiro valeramse da preparação militar e posteriormente da guerra para inserir o Brasil virtuosamente no seio da II Revolução Industrial, caracterizada pelo domínio da siderurgia e da eletricidade. 
Foi graças ao engajamento que se estabeleceu a Pax Americana - a reconstrução da Alemanha e do Japão que deram aos EUA a condição de hegemon mundial. O Plano Marshall de reconstrução da Europa permitiu que os EUA colocassem sob seu comando todas as hegemonias navais precedentes - Portugal, Espanha, Holanda e Inglaterra. Deste modo, fica claro que a cooperação, ou engajamento, é muito mais efetiva para o exercício da dominação que a confrontação ou balanceamento estrito. Contudo, logo após o discurso de Churchill em Fulton (I946) - que influenciou o anúncio da Doutrina Truman (I947) -, os EUA passaram a adotar o balanceamento, em sentido estrito, como comportamento dominante em relação à URSS e à China. Esta política foi implementada ao longo de todo o período denominado Guerra Fria (I945-I99I).

E, mais uma vez, o balanceamento estrito revelar-se-ia falho. Para derrotar a URSS, um Estado que nunca excedeu a média de 9,5\% do PIB mundial, os EUA converteram a China e a Europa em superpotências econômicas. Em suma, criaram adversários mais aptos do que aquele que pretendiam vencer. Mesmo após a debacle da URSS, os EUA mantiveram a postura de balanceamento estrito. Ao invés de uma nova versão do Plano Marshall, que financiasse a conversão da economia soviética para o capitalismo tradicional, intensificou-se a pressão militar e diplomática com a expansão da OTAN para o Leste e a busca da primazia nuclear. Hoje a URSS vê-se renascida na forma da Federação Russa e constitui-se, mais uma vez, em um adversário formidável. Justamente graças às capacidades que reativamente desenvolveu à expansão da OTAN e à busca estadunidense pela primazia nuclear. A China, por sua vez, mantinha uma relação dependente-associada aos EUA até que se deu o bombardeio da embaixada chinesa em Belgrado (I999) e o anúncio do Pivô para a Ásia (20II). Cumpre apontar que a Marinha Chinesa, que hoje ameaça a US Navy no Indo-Pacífico, foi construída de 20 II para cá.

Em suma, o balanceamento estrito revela-se, mais que falho, contraproducente. A longo prazo, produz resultados opostos ao planejado. A Prússia, da qual a Inglaterra se valeu para balancear a França, ao converter-se em Alemanha tornou-se um adversário mais imponente do que a França tinha sido. O Japão utilizado para subjugar a China e balancear a Rússia, acabou por destruir a Marinha Britânica no Indo-Pacífico (coisa que a China Imperial ou a Rússia dos czares jamais ousaram sequer sonhar).

Durante a Segunda Guerra, a procrastinação em abrir a segunda frente para travar a guerra terrestre em continente europeu, deixando a URSS combatendo sozinha contra a Alemanha, permitiu a primeira erigir-se como Superpotência. Um oponente mais formidável do que a Alemanha o foi em qualquer tempo, posto que dotada de ogivas termonucleares, a URSS era 
capaz de destruir os EUA - capacidade que a Alemanha nunca deteve. Já sob a perspectiva estadunidense, a Europa e a China, utilizadas para derrotar a URSS na Guerra Fria, converteram-se em superpotências econômicas, sendo que a primeira disputa também o poder brando com os EUA. Por fim, a Alemanha e a Rússia, contra as quais foram articuladas as duas maiores coalizações globais da história pelos esforços anglo-saxões, hoje retêm suas capacidades e a condição de integrar-se, no caso da primeira, ou consolidar-se, no caso da última, como Grande Potência.

Porém, o mais grave é que o principal resultado do balanceamento estrito foi o declínio do Ocidente. Como destacam Jeffrey Sachs e Steven Radelet $^{8}$ : em I 820 , o Ocidente contava com pouco mais de $\mathrm{I} 5 \%$ da população mundial e $25 \%$ da sua renda. Já em I950, graças ao efeito das Revoluções Industriais, as nações do Ocidente detinham apenas $17 \%$ da população mundial, mas já concentravam $56 \%$ da renda. Atualmente 9 , o Ocidente (União Europeia e América do Norte conjugados) correspondem a 33\% da renda mundial e I8\% de sua população. Enquanto as Economias da região Ásia-Pacífico contribuem para $44 \%$ da renda e $60 \%$ da população. Tomandose somente o Leste Asiático (China, Japão e Coreia do Sul), afere-se que este já participa com $25 \%$ da renda mundial e apenas $21 \%$ da população. Deste modo, é forçoso concluir que, graças a sua inserção virtuosa na III Revolução Industrial (microeletrônica), a Ásia recupera progressivamente o papel que tinha na renda mundial antes das Revoluções Industriais.

Tais lições importam para o Brasil, na medida em que se possa tirar proveito da nova situação internacional através do engajamento, da neutralidade e da barganha diplomática. Nem poderia ser diferente. Se a Segunda Guerra Mundial, travada por Estados-região contra Estados-nação relativamente diminutos, produziu 85 milhões de mortos, o que esperar de uma contenda que envolva EUA, Rússia e China? Além disso, o Brasil possui laços de interdependência econômicas tanto com os EUA quanto com a China. Sem falar no financiamento externo que depende de abundância de liquidez, que simplesmente deixaria de existir sob a égide de uma conflagração. Contudo, cumpre aproveitar a situação de tensão internacional, visando, com o uso da barganha diplomática, obter a recuperação da economia nacional, sobretudo a reindustrialização. Do mesmo modo que Vargas obteve o domínio da eletricidade, do cimento e do aço, só travando a Guerra depois que ela já estava definida, precisamos obter o domínio do computador (microprocessadores),

8 Radelet, S., Sachs, J. Asia's Reemergence. Foreign Affairs, [s. 1.], v. 76, n. 6, p. 44-59.

9 Fonte dos dados 20I7: Estados Unidos. Country Comparison: GDP (Purchasing Power Parity). CIA World Fact Book. 2020. Organização das Nações Unidas (ONU). World Population Prospects, the 2010 Revision. UN Department of Economic and Social Affairs. 2013. 
da rede (Internet 5G) e da automação (Inteligência Artificial e robótica). E, desta feita, nos inserirmos exitosamente na III Revolução Industrial.

Porto Alegre, I4 de dezembro de 2020. 